\title{
A Competitive Growth Model with Endogenous Fertility
}

\author{
Fernando A. Veloso*
}

\begin{abstract}
This paper investigates the interaction between endogenous fertility behavior and the distribution of income and wealth among families in a competitive market economy. We construct a growth model in which altruistic dynasties are heterogeneous in their initial stocks of physical capital. Dynasties make choices of family size along with decisions about consumption and intergenerational transfers. We show that, if the degree of altruism per child is decreasing in the number of children and if preferences over the number of children satisfy a normality assumption, all steady states are characterized by equality of capital stocks and consumption among families. We also show that specific functional forms for the utility function used in the fertility literature, including Becker and Barro (1988), Barro and Becker (1989), Benhabib and Nishimura (1993) and Lucas (2002), are special cases of the preference specification used in this paper. Hence, they also generate egalitarian steady states.
\end{abstract}

Key Words: fertility, wealth distribution, growth model .

JEL Code: D31, J13, 041 .

* Department of Economics, Ibmec, Av. Rio Branco 10850 andar, Rio de Janeiro-RJ, 20040001, Tel: +55 21 3806-4125, Fax: +55 21 2242-3253, E-mail: fveloso@ibmecrj.br. I thank Fernando Alvarez, Gary Becker, Nancy Stokey, two anonymous referees and especially Robert Lucas, for comments and suggestions. I also thank Avner Ahituv, seminar participants at USP, EPGE-FGV and the Growth and Development Workshop at the University of Chicago. An early version of this paper was presented at the XIX Meeting of the Brazilian Econometric Society and I am grateful to Renato Fragelli for his comments. Financial support from CAPES is gratefully acknowledged. All errors are my responsibility.

Brazilian Review of Econometrics Rio de Janeiro v.23, n⿳0 1, pp. 43-75 May 2003 
A Competitive Growth Model with Endogenous Fertility

\section{Resumo}

Este artigo investiga a interação entre fecundidade endógena e a distribuição de renda e riqueza entre famílias em uma economia competitiva. Construímos um modelo de crescimento em que dinastias altruístas são heterogêneas nos seus estoques iniciais de capital físico. Dinastias fazem escolhas sobre o tamanho da família, assim como sobre o consumo e transferências intergeracionais. Nós mostramos que, se o grau de altruísmo por filho for decrescente no número de filhos e se preferências sobre o nuimero de filhos satisfizerem uma hipótese de normalidade, todos os estados estacionários serão caracterizados por igualdade dos estoques de capital e consumo entre famílias. Também mostramos que formas funcionais específicas para a função de utilidade utilizadas na literatura, incluindo Becker e Barro (1988), Barro e Becker (1989), Benhabib e Nishimura (1993) e Lucas (2002), são casos especiais da especificação de preferências empregada neste artigo. Portanto, elas também geram estados estacionários igualitários.

\section{Introduction.}

This paper investigates the interaction between endogenous fertility behavior and the distribution of income and wealth in a competitive market economy. Specifically, we examine under which conditions endogenous fertility leads to equality of income and wealth among families in the long run.

We consider a society divided into a finite number of dynasties, in which individuals from different generations are altruistically linked. All the members of a given dynasty have the same physical capital holdings, but dynasties differ in their per capita holdings and in their size (number of members). Different dynasties interact in competitive markets for goods and factor services in each period. Parents are assumed to derive utility from their consumption, number of children and the well-being of each child.

We show that, if the degree of altruism per child is decreasing in the number of children and if preferences over the number of children satisfy a normality assumption, all steady states are characterized by equality of capital stocks and consumption among families. We also 
provide sufficient conditions for uniqueness of the steady state.

The result that all steady states are egalitarian is established in Becker and Barro (1988) for a particular functional form of preferences over the number of children. The main contribution of this paper is the generalization of the Becker-Barro model and the characterization of the assumptions about preferences and technology that are sufficient to generate equality of the long-run distribution of income and wealth in a competitive market economy.

We also show that other functional forms for the utility function used in the fertility literature, including Barro and Becker (1989), Benhabib and Nishimura (1993) and Lucas (2002), are also special cases of the preference specification used in this paper. Hence, they also generate egalitarian steady states.

The paper is organized as follows. Section 2 presents the model and defines a recursive competitive equilibrium for the economy. Section 3 defines a steady state and an egalitarian steady state and provides sufficient conditions for uniqueness of an egalitarian steady state. Section 4 analyzes a special case in which preferences over the number of children satisfy the Becker and Barro (1988) specification and the technology is of the Cobb-Douglas type. Section 5 concludes.

\section{The Model.}

The model is set up as follows. Society is divided into a finite number of dynasties. We define a dynasty or family line as a collection of agents composed of a parent and all her descendants. We assume that the economy starts out with a finite number of parents, who in turn define a finite number of dynasties, indexed by $i=1, \ldots, M$.

Agents live two periods, the first as children, in which they do not make any economic decisions, and the second as parents. Each 
period is taken to be a generation. Parents are assumed to value their consumption, the number of children they have, and the lifetime utility of each child, according to preferences given by $^{1}$ :

$$
u_{t}=W\left(c_{t}, n_{t}, u_{t+1}\right)
$$

where $c_{t}$ denotes parental consumption, $n_{t}$ denotes the number of children, $u_{t}$ is the utility of the parent and $u_{t+1}$ is the utility of each child. We assume that $W$ is continuous, strictly increasing and strictly concave in all its arguments, twice continuously differentiable, and satisfies the following discounting condition:

$$
0<W_{u}\left(c_{t}, n_{t}, u_{t+1}\right)<1 \quad \forall\left(c_{t}, n_{t}, u_{t+1}\right)
$$

We also assume that $\lim _{c_{t \rightarrow 0}} W_{c}=+\infty$ and $\lim _{n_{t \rightarrow 0}} W_{n}=+\infty$.

Parents have identical preferences and supply inelastically one unit of labor. All the currently alive members of a given dynasty have the same stock of physical capital but dynasties differ in their per capita physical capital holdings. Moreover, dynasties may differ in size (number of members).

There is a large number of firms endowed with the same constant returns to scale technology, so we can assume, without loss of generality, that there is only one firm, which produces the only consumption good according to an aggregate constant returns to scale production function, described by $Y=F(K, N)$,where $K$ and $N$ denote aggregate capital and labor, respectively.

\footnotetext{
${ }^{1}$ Recursive (but not necessarily time-additive) preferences over consumption have been used by Lucas and Stokey (1984) and Dolmas (1996) in the context of optimal growth models. The formulation presented in the text has been postulated by Alvarez (1999) and Lucas (2002) in the context of endogenous fertility models.
} 
Let $y$ and $\bar{k}$ denote output per capita and capital per capita, respectively. We assume that $y=f(\bar{k}) \equiv F(\bar{k}, 1)$ is strictly increasing, strictly concave and satisfies the Inada conditions ${ }^{2}$.

In each period, firms sell goods to the household sector and agents supply their labor at a wage rate $w$ and rent their capital to firms at a rental rate $r$. The economy is assumed to be competitive, so both agents and firms take prices as given.

In this economy, agents are indexed by the dynasty to which they belong. Let $k_{i}$ denote the capital stock of a member of dynasty $i$ and $N_{i}$ the number of members of dynasty $i$. A typical member of dynasty $i$ derives his income from the wage rate $w$ and from capital $k_{i}$, which earns rent at the rate $r$. Capital depreciates at the rate $\delta$. We assume that each child has a fixed cost $\phi$ in units of the consumption good, so $\phi n_{i}$ is the total cost of child-rearing. Parents choose a bequest $k_{i}^{\prime}$ for each child, so total bequests equal $n_{i} k_{i}^{\prime}$. Parents also spend their resources on their own consumption $c_{i}$, so their budget constraint can be written $\mathrm{as}^{3}$ :

$$
c_{i}+n_{i}\left(\phi+k_{i}^{\prime}\right)=(1-\delta+r) k_{i}+w
$$

Let $a_{i} \equiv \frac{N_{i}}{\sum_{j=1}^{M} N_{j}}$ denote the share of dynasty $i$ in the population. The state of the economy can be described by the vector $s=(k, a)$, where $k=\left(k_{1}, \ldots, k_{M}\right)$ and $a=\left(a_{1}, \ldots, a_{M}\right)$.

Let $V\left(k_{i}, s\right)$ denote the lifetime utility of a parent with capital $k_{i}$, who behaves optimally, when the state of the economy is $s$. The problem of the head of dynasty $i$ is given by:

\footnotetext{
${ }^{2}$ These conditions will be stated formally in Assumption 2 below.

${ }^{3}$ This formulation of the budget constraint incorporates the interaction between quantity and quality of children emphasized in Becker and Lewis (1973), Razin and Ben-Zion (1975), Becker and Barro (1988), Barro and Becker (1989), Benhabib and Nishimura (1993), Alvarez (1999) and Lucas (2002).
} 
A Competitive Growth Model with Endogenous Fertility

$$
\begin{aligned}
V\left(k_{i}, s\right)= & \max _{c_{i} \geq 0, n_{i} \geq 0, k_{i}^{\prime} \geq 0} W\left(c_{i}, n_{i}, V\left(k_{i}^{\prime}, h(s)\right)\right) \\
& \text { s.t. } \\
& c_{i}+n_{i}\left(\phi+k_{i}^{\prime}\right)=(1-\delta+r(s)) k_{i}+w(s)
\end{aligned}
$$

where $r(s)$ is the real rental rate of capital, expressed as a function of the state $s$ and $w(s)$ is the real wage rate, also expressed as a function of the state $s$. The function $h$ describes the law of motion of the state, assumed to be known by the agents. Each dynasty takes wages and rental rates as given. The solution to this problem yields optimal decision rules described by the functions

$$
k_{i}^{\prime}=b\left(k_{i}, s\right), n_{i}=n\left(k_{i}, s\right), c_{i}=c\left(k_{i}, s\right)
$$

Competition and profit maximization by firms together imply that factors are paid their marginal products and firms earn zero profits. These conditions define the functions

$$
\begin{gathered}
r(s)=r(k, a)=f^{\prime}\left(\sum_{i=1}^{M} a_{i} k_{i}\right) \\
w(s)=w(k, a)=f\left(\sum_{i=1}^{M} a_{i} k_{i}\right)-\left(\sum_{i=1}^{M} a_{i} k_{i}\right) f^{\prime}\left(\sum_{i=1}^{M} a_{i} k_{i}\right)
\end{gathered}
$$

Definition 1. A recursive competitive equilibrium is a value function $V: R_{+}^{2 M+1} \rightarrow R$, policy functions $b: R_{+}^{2 M+1} \rightarrow R_{+}, n$ : $R_{+}^{2 M+1} \rightarrow R_{+}, c: R_{+}^{2 M+1} \rightarrow R_{+}$, and an economy-wide law of motion $h: R_{+}^{2 M} \rightarrow R_{+}^{2 M}$ for the state $s$, such that: 
1) $V$ satisfies (1), given $h$.

2) $b, n$ and $c$ are optimal decision rules, that is, they solve (1), for given $h$.

3) the law of motion $h$ satisfies the following rational expectations condition:

$$
\begin{array}{r}
\forall s, h(s)=\left(b\left(k_{1}, s\right), \ldots, b\left(k_{M}, s\right), \frac{n\left(k_{1}, s\right)}{\sum_{i=1}^{M} a_{i} n\left(k_{i}, s\right)} a_{1}, \ldots,\right. \\
\left.\frac{n\left(k_{M}, s\right)}{\sum_{i=1}^{M} a_{i} n\left(k_{i}, s\right)} a_{M}\right)
\end{array}
$$

Instead of characterizing the recursive competitive equilibrium defined above, we will focus instead on steady state equilibria.

\section{Steady State.}

Definition 2. A steady state is a state $s^{*}=\left(k^{*}, a^{*}\right)$ such that:

$$
h\left(s^{*}\right)=s^{*}
$$

where $h$ is the equilibrium law of motion of the state. This definition states that, in a steady state, the capital stocks and population shares of all dynasties are constant ${ }^{4}$. Notice that, in a steady state, the following must hold:

\footnotetext{
${ }^{4}$ It should be noticed that the requirement that the population shares of all dynasties be constant in a steady state immediately implies that the steady state fertility rate is the same for all families. In this model, this result would be obtained even if it were not part of the definition of a steady state. In any case, since $a$ is a component of the state of the economy, $s$, it is necessary that it be constant in a steady state. Otherwise, the average capital stock and factor prices might be changing in steady state.
} 
A Competitive Growth Model with Endogenous Fertility

i) $k_{i}^{*}=b\left(k_{i}^{*}, s^{*}\right), \quad \forall i=1, \ldots, M$

ii) for some $\lambda>0, \lambda=n\left(k_{i}^{*}, s^{*}\right) \quad \forall i=1, \ldots, M$.

where $(b, n)$ are the policy functions for a recursive competitive equilibrium. Condition (i) states that, for each dynasty, it is optimal to maintain the capital stock at its steady state level. Condition (ii) states that, in a steady state, all dynasties grow at a common rate, $\lambda$, which is the optimal fertility rate given the distribution of capital and population shares among dynasties.

Definition 3. An egalitarian steady state is a steady state with $k_{i}^{*}=k_{j}^{*} \quad \forall i, j=1, \ldots, M$.

In a steady state, the rental rate of capital and the wage rate will be constant at $r$ and $w$, respectively, since the economy-wide per capita capital stock, $\bar{k}^{*} \equiv \sum_{i=1}^{M} a_{i}^{*} k_{i}^{*}$, is constant.

Remark 1. Let $V\left(k_{i}, s^{*}\right)$ denote the lifetime utility attained by an adult member of dynasty $i$ in a steady state. Since the distribution of capital and population shares is constant in a steady state, the optimum value function of a parent depends upon $s^{*}$ only through $\bar{k}^{*}$, the economy-wide per capita capital stock ${ }^{5}$. Hence, we can define a function $\tilde{V}$ satisfying $\tilde{V}\left(k_{i}, \bar{k}^{*}\right) \equiv V\left(k_{i}, s^{*}\right)$ for all $s^{*}=\left(k_{1}^{*}, \ldots, k_{M}^{*}, a_{1}^{*}, \ldots, a_{M}^{*}\right)$ such that $\bar{k}^{*}=\sum_{i=1}^{M} a_{i}^{*} k_{i}^{*}$.

Consider the decision problem of the head of dynasty $i$ when the economy is at a steady state. Let $v\left(k_{i}\right) \equiv \tilde{V}\left(k_{i}, \bar{k}\right)$. Then $v\left(k_{i}\right)$ satisfies the following functional equation:

$$
\begin{aligned}
v\left(k_{i}\right)= & \max W\left(c_{i}, n_{i}, v\left(k_{i}^{\prime}\right)\right) \\
& \text { s.t. } \\
& c_{i}+n_{i}\left(\phi+k_{i}^{\prime}\right)=R k_{i}+w
\end{aligned}
$$

\footnotetext{
${ }^{5}$ This follows from the assumption that the production function exhibits constant returns to scale and the fact that the population share does not enter the decision problem of a parent.
} 
where $R \equiv 1-\delta+r=1-\delta+f^{\prime}(\bar{k})$ and $w=f(\bar{k})-\bar{k} f^{\prime}(\bar{k})^{6}$. The first-order conditions corresponding to this problem are:

$$
\begin{aligned}
& n_{i} W_{c}\left(c_{i}, n_{i}, v\left(k_{i}^{\prime}\right)\right)=W_{u}\left(c_{i}, n_{i}, v\left(k_{i}^{\prime}\right)\right) v^{\prime}\left(k_{i}^{\prime}\right) \\
& W_{n}\left(c_{i}, n_{i}, v\left(k_{i}^{\prime}\right)\right)=W_{c}\left(c_{i}, n_{i}, v\left(k_{i}^{\prime}\right)\right)\left(\phi+k_{i}^{\prime}\right)
\end{aligned}
$$

Equation (7) equates the marginal cost of an additional unit of bequest to its marginal benefit. Notice that the marginal utility of consumption in the left-hand side of (7) is multiplied by the fertility rate, because of the interaction between bequests and the number of children in the budget constraint.

Equation (8) equates the marginal utility of children to its marginal cost. Notice that the bequest per child $k_{i}^{\prime}$ increases the marginal cost of children, again because of the interaction between quantity and quality of children in the budget constraint.

The envelope condition is:

$$
v^{\prime}\left(k_{i}\right)=W_{c}\left(c_{i}, n_{i}, v\left(k_{i}^{\prime}\right)\right) R
$$

Let $u_{i}=v\left(k_{i}\right)$. From (6)-(9) and the definition of a steady state, we can characterize the steady state with the following system of equations:

$$
\begin{array}{cc}
u_{i}=W\left(c_{i}, \lambda, u_{i}\right) & i=1, \ldots, M \\
R W_{u}\left(c_{i}, \lambda, u_{i}\right)=\lambda & i=1, \ldots, M
\end{array}
$$

${ }^{6}$ Henceforth, I will drop the superscript $*$ that has been used to denote steady state values, in order to simplify the notation. 
A Competitive Growth Model with Endogenous Fertility

$$
\begin{aligned}
& \frac{W_{n}\left(c_{i}, \lambda, u_{i}\right)}{W_{c}\left(c_{i}, \lambda, u_{i}\right)}=\phi+k_{i} \quad i=1, \ldots, M \\
& c_{i}+\lambda\left(\phi+k_{i}\right)=R k_{i}+w \quad i=1, \ldots, M \\
& R=1-\delta+f^{\prime}(\bar{k}) \\
& w=f(\bar{k})-\bar{k} f^{\prime}(\bar{k}) \\
& \bar{k}=\sum_{i=1}^{M} a_{i} k_{i} \\
& \sum_{i=1}^{M} a_{i}=1
\end{aligned}
$$

Equations (13)-(17) imply:

$$
f(\bar{k})+(1-\delta) \bar{k}=\sum_{i=1}^{M} a_{i} c_{i}+(\phi+\bar{k}) \lambda
$$

Assumption 1. The utility function $W: R_{+}^{3} \rightarrow R$ is defined by $W(c, n, u)=\hat{W}(c, n)+\varphi(n) u$. The function $\hat{W}: R_{+}^{2} \rightarrow R$ is continuous, twice continuously differentiable, strictly increasing and strictly concave ${ }^{\gamma}$ in $(c, n)$, and satisfies $\lim _{c \rightarrow 0} \hat{W}_{c}=+\infty$ and $\lim _{n \rightarrow 0} \hat{W}_{n}=$ $+\infty$. The function $\varphi: R_{+} \rightarrow R_{+}$is continuous, strictly increasing,

\footnotetext{
${ }^{7}$ All the results in this paper could also be obtained if we assumed that $\hat{W}$ is quasi-concave.
} 
twice continuously differentiable, and satisfies $\varphi(0)=0,0<\varphi<1$, $0<\varphi^{\prime}<1$, and $\varphi^{\prime \prime}<0$ for all $n>0$ as well as $\lim _{n \rightarrow 0} \varphi^{\prime}(n)=+\infty$.

The term $\varphi(n)$ converts the utility of children into that of parents, and can be interpreted as measuring the degree of altruism of parents towards children. Assumption 1 implies that $\varphi(n) / n$ is strictly decreasing in $n$, that is, $\varphi-\varphi^{\prime} n>0$. This corresponds to the assumption that the degree of altruism per child is decreasing in the number of children.

In order to gain some intuition on the implications of this hypothesis, we can use the preference specification defined in Assumption 1 and rewrite (11) as

$$
R \frac{\varphi(\lambda)}{\lambda}=1
$$

This condition shows that the steady state degree of altruism per child, $\frac{\varphi(\lambda)}{\lambda}$, may be interpreted as an "effective discount factor", in the sense that it is the factor at which families effectively discount the future.

The assumption of decreasing altruism per child means that the total degree of altruism increases with the number of children at a decreasing rate. This assumption seems reasonable, for at least two reasons $^{8}$. First, it implies that, for a given level of utility per child $u$, parental utility is strictly concave in $n^{9}$.

Second, it is important to notice that this assumption is satisfied if $\varphi(n)=\beta, 0<\beta<1$, which corresponds to the standard

\footnotetext{
${ }^{8}$ As will be discussed in section 4 , the functional forms for the utility function most widely used in the fertility literature incorporate this assumption.

${ }^{9}$ If children do not yield utility directly through the function $\hat{W}$, the assumption of decreasing altruism per child is not only sufficient but also necessary so that concavity of the utility function in $n$ is obtained.
} 
A Competitive Growth Model with Endogenous Fertility

assumption that the discount factor is constant. This shows that the assumption of decreasing altruism per child is less restrictive than it seems.

Assumption 2. The production function $f: R_{+} \rightarrow R_{+}$is continuous, twice continuously differentiable, and satisfies $f(0)=0$, $f^{\prime}>0$, and $f^{\prime \prime}<0$ for all $\bar{k}>0$ as well as $\lim _{\bar{k} \rightarrow 0} f^{\prime}(\bar{k})=+\infty$ and $\lim _{\bar{k} \rightarrow+\infty} f^{\prime}(\bar{k})=0$.

In order to solve for the steady state, we will use the following strategy. First, we will postulate an economy-wide capital stock per capita $\bar{k}$. From (14) and (15), we can express the interest rate $R$ and the wage rate $w$ as functions of $\bar{k}$ :

$$
\begin{aligned}
& R=R(\bar{k}) \equiv 1-\delta+f^{\prime}(\bar{k}) \\
& w=w(\bar{k}) \equiv f(\bar{k})-\bar{k} f^{\prime}(\bar{k})
\end{aligned}
$$

Using (10)-(13), we will solve for $c_{i}, k_{i}, u_{i}$ and $\lambda$ for a given pair $(R, w)$. Using (19) and (20), we will define a mapping from $\bar{k}$ to the individual capital stock $k_{i}, k_{i}=\Psi(\bar{k})$. Then we will use (16) and (17) to solve for the equilibrium $\bar{k}$.

Consider a member of a dynasty $i$. Given the preference structure assumed above, (10) becomes

$$
u_{i}=\hat{W}\left(c_{i}, \lambda\right)+\varphi(\lambda) u_{i}
$$

From (21) and using the discounting assumption $0<\varphi(n)<1$, we can solve for $u_{i}$ as a function of $(c, \lambda)$ :

$$
u_{i}=\frac{\hat{W}\left(c_{i}, \lambda\right)}{1-\varphi(\lambda)} \equiv g\left(c_{i}, \lambda\right) \quad g_{c}>0, g_{\lambda}>0
$$


The derivatives of $g$ have the signs above because of the assumptions that $\hat{W}$ is strictly increasing in $c$ and $\lambda$ and $\varphi^{\prime}(\lambda) \geq 0$.

After substituting (22) into the left-hand side of (12) and using the functional form for $W$ from assumption 1 , we can write the steady state marginal rate of substitution between children and consumption as a function of steady state consumption and fertility as follows:

$$
m\left(c_{i}, \lambda\right) \equiv \frac{\hat{W}_{n}\left(c_{i}, \lambda\right)+\varphi^{\prime}(\lambda) g\left(c_{i}, \lambda\right)}{\hat{W}_{c}\left(c_{i}, \lambda\right)}
$$

From (13), we can write $k_{i}$ as a function of $c_{i}$ and $\lambda$ (for given $R$ and $w)$ :

$$
k_{i}=\frac{c_{i}+\phi \lambda-w}{R-\lambda}
$$

If we substitute (23) and (24) into (12), we obtain

$$
m\left(c_{i}, \lambda\right)=\frac{\phi R+c_{i}-w}{R-\lambda}
$$

Given the assumed preference structure, (11) can be rewritten as:

$$
R=\frac{\lambda}{\varphi(\lambda)}
$$

Since $\frac{\varphi(\lambda)}{\lambda}$ is strictly decreasing in $\lambda$, we can solve (26) for $\lambda$ as a function of $R, \lambda=\xi(R)$, where $\xi(R)$ satisfies:

$$
R \equiv \frac{\xi(R)}{\varphi(\xi(R))}
$$


A Competitive Growth Model with Endogenous Fertility

Differentiating (27) implicitly with respect to $R$, we obtain

$$
\xi^{\prime}(R)=\frac{\lambda^{2}}{R^{2}\left(\varphi-\varphi^{\prime} \lambda\right)}>0
$$

since $\varphi-\varphi^{\prime} \lambda>0$. If we use (27) to substitute for $\lambda$ in (25), we obtain:

$$
m\left(c_{i}, \xi(R)\right)=\frac{\phi R+c_{i}-w}{R(1-\varphi(\xi(R)))}
$$

We want to find restrictions on $W$ such that (28) defines $c_{i}$ as a function of $(R, w)$, where $W$ is defined in assumption 1. Throughout this analysis, we will keep $(R, w)$ constant and view both sides of (28) as functions of $c_{i}$.

Remark 2. From assumption 2, there exists a $\tilde{k}>0$ such that $\bar{k} \leq f(\bar{k}) \leq \tilde{k}$ for all $0 \leq \bar{k} \leq \tilde{k}$, and $f(\tilde{k})<\tilde{k}$ for all $\tilde{k}>\tilde{k}$. Hence, $X=[0, \tilde{k}]$ is the set of maintainable capital stocks ${ }^{10}$.

Assumption 3. Assume that $\phi R(\tilde{k})-w(\tilde{k})>0$, where $\tilde{k}$ is defined as in Remark 2.

Remark 3. Since $w(\bar{k}) / R(\bar{k})$ is strictly increasing in $\bar{k}$, assumption 3 implies that $\phi R(\bar{k})-w(\bar{k})>0 \forall \bar{k} \in X$.

Assumption 3 imposes a lower bound on the cost of child-rearing $\phi$, given by $\frac{w(\bar{k})}{R(\bar{k})}$. One way to interpret this assumption is that it requires the net cost of producing a descendant to be positive. An additional child costs $\phi$ in the current period, which is worth $R \phi$ next period. Since an additional descendant will earn $w$ next period, when she becomes an adult, the net cost of an additional adult is $\phi R-w$, which is positive from assumption 3 .

${ }^{10}$ See Stokey and Lucas (1989). 


\section{Fernando A. Veloso}

Assumption $4 \varepsilon\left(c_{i}, \lambda\right) \equiv \frac{m_{c}\left(c_{i}, \lambda\right) c_{i}}{m\left(c_{i}, \lambda\right)} \geq 1$ fol all $\left(c_{i}, \lambda\right)$ satisfying
(10)-(17).

Lemma 1 states that, in any steady state, $c_{i}=c_{j} \forall i, j=$ $1, \ldots, M$.

Lemma 1. Let assumptions 1-4 hold. Then there is at most one $c_{i}$ that solves (28) for given $(R, w)$.

Proof: See Appendix.

Let $\Omega\left(c_{i}, \lambda\right) \equiv \frac{m\left(c_{i}, \lambda\right)}{c_{i}}$ as defined in the Appendix. The derivative of $\Omega\left(c_{i}, \lambda\right)$ with respect to $c_{i}$ can be related to the aggregator $W$ as follows:

$\Omega_{c}\left(c_{i}, \lambda\right)=\frac{\left[\hat{W}_{c} \hat{W}_{c n}-\left(\hat{W}_{n}+\varphi^{\prime} g\right) \hat{W}_{c c}\right.}{\left(\hat{W}_{c}\right)^{2} c_{i}^{2}}$

where all derivatives are evaluated at steady state values. As shown in the Appendix, assumption 4 implies that $\Omega_{c} \geq 0$, which guarantees that a unique $c_{i}$ solves (28).

To gain some intuition on the restriction imposed on $\varepsilon\left(c_{i}, \lambda\right)$, consider the following problem ${ }^{11}$ :

$$
\begin{aligned}
\max _{c, n} & \hat{W}(c, n)+\varphi(n) u \\
& \text { s.t. } \\
& c+n\left(\phi+k^{\prime}\right)=I
\end{aligned}
$$

where $I$ is income. In this problem, $k^{\prime}$ is held constant, so $u=v\left(k^{\prime}\right)$ is a parameter ${ }^{12}$.

\footnotetext{
${ }^{11}$ The following argument is motivated by a similar reasoning in Lucas (2002).

${ }^{12}$ This problem is a version of the problem stated in (6), with bequests per child $k^{\prime}$ taken as given.
} 
Definition 4. $n$ is normal if the maximizing value of $n$ in (30) is increasing in $I$ for all values of $\phi$ and $k^{\prime}$. This is equivalent to the condition $\hat{W}_{c} \hat{W}_{c n}-\left(\hat{W}_{n}+\varphi^{\prime} g\right) \hat{W}_{c c} \geq 0^{13}$.

Definition 5. $n$ and $u$ are complements if the maximizing value of $n$ in (30) is increasing in $u$ for all values of $\phi$ and $k^{\prime}$. This is equivalent to the condition $\hat{W}_{c} \varphi^{\prime} \geq 0^{14}$.

If we assume that $n$ is normal and $n$ and $u$ are complements in the sense defined above, the first term in the numerator of (29) will be positive at the steady state solution, since $g_{c}>0$. Yet, these conditions are not enough to guarantee that $\Omega_{c} \geq 0$ and hence the existence of a unique $c_{i}$ satisfying (28), since the second term in the numerator of (29) is also positive. Hence, we need the stronger condition $\varepsilon\left(c_{i}, \lambda\right) \geq 1$.

The intuition for this result is the following. Richer dynasties desire to have more children, since children are a normal good. Yet, they also face a higher price of children, because they invest more in each child. Hence, it might be possible to have a steady state in which two dynasties with different capital stocks and consumption find it optimal to have the same number of children.

In order to have an egalitarian steady state, we need a stronger normality assumption, described by Assumption 4. This normality assumption implies that fertility increases with income even after the negative effect due to the quantity-quality tradeoff is accounted for $^{15}$.

\footnotetext{
${ }^{13}$ This condition can be obtained by differentiating implicitly the first-order conditions associated with (30) with respect to $I$ and by requiring that the derivative of the maximizing value of $n$ with respect to $I$ be positive. See the Appendix for a formal derivation.

${ }^{14}$ This condition can be obtained by differentiating implicitly the first-order conditions associated with (30) with respect to $u$ and by requiring that the derivative of the maximizing value of $n$ with respect to $u$ be positive. See the Appendix for a formal derivation.

${ }^{15}$ This normality assumption is analogous to the concept of "observed normality" developed in
} 
In light of Lemma 1, we can define $c_{i}$ as a function of $(R, w), c_{i}=$ $\pi(R, w)$. The following proposition states that all steady states are egalitarian.

Proposition 1. Let assumptions 1-4 hold. Then all steady states are egalitarian, that is, they satisfy $k_{i}=k_{j} \quad \forall i, j=1, \ldots, M$.

Proof: See Appendix.

Intuitively, the implication that all steady states are egalitarian follows from the assumptions that fertility increases with income and that larger families discount more the utility of each child. It should be noted, however, that assumptions 1-4 only establish sufficient conditions for all steady states to be egalitarian.

We consider next the issue of uniqueness of the steady state. From (19) and (26), we can define $\lambda$ as a function of $\bar{k}, \lambda \equiv \xi(R(\bar{k})) \equiv$ $\lambda(\bar{k})$, where $\lambda(\bar{k})$ satisfies:

$$
\frac{\lambda(\bar{k})}{\varphi(\lambda(\bar{k}))} \equiv R(\bar{k})
$$

Differentiating (31) implicitly with respect to $\bar{k}$, we obtain:

$$
\lambda^{\prime}(\bar{k})=\frac{\lambda^{2}}{R^{2}\left(\varphi-\varphi^{\prime} \lambda\right)} R^{\prime}(\bar{k})
$$

Since $\varphi-\varphi^{\prime} \lambda>0$ and $R^{\prime}(\bar{k})=f^{\prime \prime}(\bar{k})<0$, we obtain that $\lambda^{\prime}(\bar{k})<0$. Equation (32) states that when the economy-wide capital stock per capita is higher, the fertility rate is lower. The reason is that a higher $\bar{k}$ reduces the interest rate, so fertility has to be lower in order to reduce the effective rate of time preference.

From (19), (20) and equation (A1) in the Appendix, we can define $c_{i}$ as a function of $\bar{k}, c_{i}=C(\bar{k})$, where $C(\bar{k})$ satisfies:

Becker and Lewis (1973). 
A Competitive Growth Model with Endogenous Fertility

$\Omega(C(\bar{k}), \xi(R(\bar{k})))=\frac{1}{R(\bar{k})\{1-\varphi[\xi(R(\bar{k}))]\}}+\frac{\phi-\Gamma(\bar{k})}{\{1-\varphi[\xi(R(\bar{k}))]\} C(\bar{k})}$

where $\Gamma(\bar{k}) \equiv \frac{w(\vec{k})}{R(\bar{k})}$.

Definition 6. $c$ is normal if the maximizing value of $c$ in (30) is increasing in $I$ for all values of $\phi$ and $k^{\prime}$. This is equivalent to the condition $\left(\hat{W}_{n}+\varphi^{\prime} g\right) \hat{W}_{c n}-\hat{W}_{c}\left(\hat{W}_{n n}+\varphi^{\prime \prime} g\right) \geq 0^{16}$.

Assumption 5. $\left(\hat{W}_{n}+\varphi^{\prime} g\right) \hat{W}_{c n}-\hat{W}_{c}\left(\hat{W}_{n n}+\varphi^{\prime \prime} g\right) \geq 0(c$ is normal).

Lemma 2. Let assumptions 1-5 hold. Then $C(\bar{k})$ is strictly decreasing in $\bar{k}$.

Proof: See Appendix.

The intuition for this result is the following. A higher $\bar{k}$ is associated with lower fertility, which raises the marginal rate of substitution between number of children and consumption, from the assumption that $c$ is normal. The normality condition on fertility requires that consumption decline. A change in $\bar{k}$ also affects the cost of fertility through changes in $w$ and $R$. By using the fact that, in equilibrium, $R$ and $w$ are related to marginal productivities, we can observe that the net (negative) effect of an increase in the wage rate on the cost of child-rearing dominates, which reduces consumption further.

From (19), (20) and (24) and substituting $c_{i}=C(\bar{k})$ and $\lambda=$ $\lambda(\bar{k})$, we can write $k_{i}$ as a function of $\bar{k}, k_{i}=\Psi(\bar{k})$, which satisfies:

${ }^{16}$ This condition can be obtained by differentiating implicitly the first-order conditions associated with (30) with respect to $I$ and by requiring that the derivative of the maximizing value of $c$ with respect to $I$ be positive. See the Appendix for a formal derivation. 


$$
\Psi(\bar{k}) \equiv \frac{C(\bar{k})+\phi \lambda(\bar{k})-w(\bar{k})}{R(\bar{k})-\lambda(\bar{k})}
$$

Since $k_{i}=k_{j} \quad \forall i, j=1, \ldots, M,(16),(17)$ and (34) imply that the steady state economy-wide capital stock per capita $\bar{k}$ must satisfy the following condition:

$$
\Psi(\bar{k})=\bar{k}
$$

Equation (35) equates the desired individual capital stock to the economy-wide capital stock per capita. The next proposition provides conditions under which (35) has a unique solution for $\bar{k}$.

Proposition 2. Let assumptions 1-5 hold. Then there exists at most one steady state economy-wide capital stock per capita $\bar{k}$.

Proof. See Appendix.

\section{Becker-Barro Preferences ${ }^{17}$.}

Let $W(c, n, u)=c^{\sigma}+\beta n^{1-\varepsilon} u \quad 0<\beta<1 \quad 0<\varepsilon<1 \quad 0<\sigma<1$ $\sigma+\varepsilon<1$

Let $f(\bar{k})=A \bar{k}^{\alpha} \quad A>0 \quad 0<\alpha<1 \quad \delta=1$

For this specification of preferences, the altruism function is given by $\varphi(n)=\beta n^{1-\varepsilon}$. It is straightforward to verify that assumption 1 is satisfied. In particular, $\frac{\varphi(n)}{n}=\frac{\beta}{n^{\varepsilon}}$ is strictly decreasing in $n$. In order for $0<\varphi(n)=\beta n^{1-\varepsilon}<1$, it is necessary that $0<n<\left(\frac{1}{\beta}\right)^{\frac{1}{1-\varepsilon}}$. In order for $0<\varphi^{\prime}(n)=(1-\varepsilon) \beta n^{-\varepsilon}<1$, it is necessary that $n>[\beta(1-\varepsilon)]^{\frac{1}{\varepsilon}}$. These conditions imply that $n$

${ }^{17}$ These preferences have been studied in Becker and Barro (1988), Barro and Becker (1989) and Becker, Murphy and Tamura (1990). 
A Competitive Growth Model with Endogenous Fertility

should be restricted to the open interval $\left([\beta(1-\varepsilon)]^{\frac{1}{\varepsilon}},\left(\frac{1}{\beta}\right)^{\frac{1}{1-\varepsilon}}\right)^{18}$. It is also clear that assumption 2 is satisfied.

In this example, the function $g\left(c_{i}, \lambda\right)$, which gives the steady state lifetime utility $u_{i}$ as a function of steady state consumption and fertility, is given by:

$$
u_{i}=g\left(c_{i}, \lambda\right)=\frac{c_{i}^{\sigma}}{1-\beta \lambda^{1-\varepsilon}}, \text { so } g_{c}>0 \text { and } g_{\lambda}>0
$$

The steady state marginal rate of substitution between number of children and consumption is given by:

$$
\frac{W_{n}\left(c_{i}, \lambda, u_{i}\right)}{W_{c}\left(c_{i}, \lambda, u_{i}\right)}=\frac{\beta(1-\varepsilon) \lambda^{-\varepsilon} u_{i}}{\sigma c_{i}^{\sigma-1}}
$$

Substituting (36) into (37), we obtain $m\left(c_{i}, \lambda\right)$, which gives the steady state marginal rate of substitution between children and consumption as a function of steady state consumption and fertility:

$$
m\left(c_{i}, \lambda\right)=\frac{\beta(1-\varepsilon) \lambda^{-\varepsilon} c_{i}}{\sigma\left(1-\beta \lambda^{1-\varepsilon}\right)}
$$

which is strictly increasing in $c_{i}$. For the Becker-Barro preferences, the function $\Omega\left(c_{i}, \lambda\right) \equiv \frac{m\left(c_{i}, \lambda\right)}{c_{i}}$ is given by

$$
\Omega\left(c_{i}, \lambda\right)=\frac{\beta(1-\varepsilon) \lambda^{-\varepsilon}}{\sigma\left(1-\beta \lambda^{1-\varepsilon}\right)}
$$

which does not depend on $c_{i}$. From (38), we have $\varepsilon\left(c_{i}, \lambda\right) \equiv$ $\frac{m_{c}\left(c_{i}, \lambda\right) c_{i}}{m\left(c_{i}, \lambda\right)}=1$.

${ }^{18}$ The comments of an anonymous referee were helpful to clarify the implications of Assumption 1 for the Becker-Barro preferences. 
Hence, assumption 4 is satisfied. We have to verify which restriction on $\phi$ is imposed by assumption 3. The maximum sustainable level of the economy-wide capital stock per capita, $\tilde{k}$, satisfies

$$
f(\tilde{k})=A \tilde{k}^{\alpha}=\tilde{k}
$$

This implies $\tilde{k}=A^{\frac{1}{1-\alpha}}$. Assumption 3 requires

$$
\phi>\frac{w(\tilde{k})}{R(\tilde{k})}=\frac{(1-\alpha)}{\alpha} \tilde{k}
$$

This implies $\phi>\frac{(1-\alpha)}{\alpha} A^{\frac{1}{1-\alpha}}$. Assumption 5 amounts to $W_{n n}=$ $-\varepsilon \beta(1-\varepsilon) \lambda^{-(1+\varepsilon)} g<0$, which holds in this case since $\beta>0$ and $0<\varepsilon<1$.

Hence, assumptions 1-5 are satisfied for the Becker-Barro preferences. From propositions 1 and 2, it follows that, for this combination of preferences and technology, there exists at most one steady state and it is necessarily egalitarian.

We can calculate the egalitarian steady state as a function of factor prices by solving the subsystem (10)-(13). Solving (11) for the Becker-Barro preferences, we obtain

$$
\lambda=(\beta R)^{\frac{1}{\epsilon}} \equiv \xi(R)
$$

Equation (40) gives the steady state fertility rate for a given $R$. Substituting (40) into (38), we obtain

$$
m\left(c_{i}, \lambda\right)=\frac{(1-\varepsilon) c_{i}}{\sigma(R-\lambda)}
$$

Substituting the expression above into (25) and solving for $c_{i}$, we obtain 
A Competitive Growth Model with Endogenous Fertility

$$
c_{i}=\frac{\sigma}{1-\varepsilon-\sigma}(\phi R-w)
$$

Equation (41) gives the steady state per capita consumption for given $(R, w)$. It is clear from (41) that all families have the same steady state consumption. Substituting (19) with $\delta=1$ and $f^{\prime}(\bar{k})=\alpha A \bar{k}^{\alpha-1}$ into (40), we have

$$
\lambda=\lambda(\bar{k}) \equiv(\alpha \beta A)^{\frac{1}{\varepsilon}}(\bar{k})^{\frac{\alpha-1}{\varepsilon}}
$$

Differentiating (42) with respect to $\bar{k}$, we obtain

$$
\lambda^{\prime}(\bar{k})=\frac{(\alpha-1)}{\varepsilon}(\alpha \beta A)^{\frac{1}{\varepsilon}}(\bar{k})^{\frac{\alpha-1-\varepsilon}{\varepsilon}}
$$

Since $\beta>0, A>0, \varepsilon>0$ and $0<\alpha<1$, it follows that $\lambda^{\prime}(\bar{k})<0$, as obtained in the general model presented in section 3 (equation (32)). Substituting (19) with $\delta=1$ and (20) into (41) and using the Cobb-Douglas specification for the production function, we obtain

$$
c_{i}=C(\bar{k}) \equiv \frac{\sigma}{(1-\varepsilon-\sigma)}\left[\phi-\frac{(1-\alpha)}{\alpha} \bar{k}\right] \alpha A \bar{k}^{\alpha-1}
$$

Differentiating (44) with respect to $\bar{k}$, we have

$$
C^{\prime}(\bar{k})=\frac{\sigma}{(1-\varepsilon-\sigma)}\left\{-(1-\alpha) A \bar{k}^{\alpha-1}+\left[\phi-\frac{(1-\alpha)}{\alpha} \bar{k}\right] \alpha(\alpha-1) A \bar{k}^{\alpha-2}\right\}
$$

Since $0<\alpha<1$ and $\phi>\frac{w}{R}=\frac{(1-\alpha)}{\alpha} \bar{k} \quad \forall \bar{k}$, we obtain from (45) that $C^{\prime}(\bar{k})<0$, as in the general model presented in section 3. 
Substituting (43) and (45) into equation (A14) in the Appendix and using the Cobb-Douglas specification for the production function, we obtain that $\Psi^{\prime}(\bar{k})<0$, as in section 3 , which establishes the uniqueness of the steady state.

The result that all steady states are egalitarian for the BeckerBarro preferences is established in Becker and Barro (1988). The result on uniqueness of the steady state is proved in a different way in Barro and Becker (1989), in the context of a neoclassical growth model with exogenous technological progress.

By characterizing the Becker-Barro preferences as special cases of the preference specification used in this paper, we have shown which are the assumptions on preferences and technology that are crucial to generate the implications in Becker and Barro (1988) and Barro and Becker (1989) about uniqueness and equality of steady states.

It is straightforward to observe that other functional forms for the utility function used recently in the fertility literature, including Benhabib and Nishimura (1993) and Lucas (2002), are also special cases of the preference specification used in this paper ${ }^{19}$. Hence, they also generate egalitarian steady states.

\section{Conclusion.}

In this paper, we constructed a growth model in which altruistic dynasties are heterogeneous in their initial stocks of physical capital. Parents make choices of family size along with decisions about

${ }^{19}$ Benhabib and Nishimura (1993) use the utility function $W(c, n, u)=c^{\sigma}+\varphi(n) u$ and Lucas (2002) assumes that $W(c, n, u)=(1-\beta) \log c+\eta \log n+\beta u$. Strictly speaking, the specification in Lucas (2002) does not satisfy all the conditions stated in Assumption 1. However, since $0<\beta<1$ and $\frac{\varphi(n)}{n}$ is strictly decreasing in $n$, all the results established in Section 3 are valid for Lucas's specification. 
consumption and intergenerational transfers. We showed that, if the degree of altruism per child is decreasing in the number of children and preferences satisfy a normality assumption, then all families have the same stock of physical capital per capita in the long run. Moreover, this common level of the capital stock is unique.

We also showed that specific functional forms for the utility function used recently in the fertility literature, including Becker and Barro (1988), Barro and Becker (1989), Benhabib and Nishimura (1993) and Lucas (2002), are special cases of the preference specifcation used in this paper.

The main contribution of this paper is to characterize which are the assumptions about preferences and technology that are captured by the specific functional forms used in the fertility literature and which are sufficient to generate uniqueness and equality of the long-run distribution of income and wealth in a competitive market economy.

Even though the contribution of the paper is theoretical, it has some empirical implications which we intend to address in future research. Specifically, in the model presented in this paper the equality of wealth and income among families in the long run is due to the fact that fertility increases with income and that larger families discount more the utility of each child. The model thus suggests that, to the extent that families derive their income from physical capital, the number of children tends to increase with income and fertility is an equalizing force.

Several other studies have shown, however, that if families are heterogeneous in their human capital stocks, the number of children tends to decline with income and fertility behavior tends to generate long-run inequality ${ }^{20}$. The reason is that human capital increases the

${ }^{20}$ See Becker, Murphy and Tamura (1990), Dahan and Tsiddon (1998), Kremer and Chen (2000) 
opportunity cost of child-rearing, and thus has a negative substitution effect on fertility. This implies that families with higher stocks of human capital have smaller families and discount less the utility of each child.

A few empirical studies have documented a positive correlation between family income and fertility ${ }^{21}$. However, most of the empirical studies find a negative correlation between fertility and family income $^{22}$. The studies that find a positive relation between fertility and income usually control for variables that are related to the productivity of the household in the marketplace, especially wages and the level of education. When these variables are not controlled for, a negative relation between fertility and family income is usually observed.

However, there is some empirical evidence of important nonlinearities in the relationship between fertility and income. In particular, some studies have documented a U-shaped relationship between fertility and income ${ }^{23}$.

The model presented in this paper suggests that the observed positive relationship between fertility and income for rich families may reflect the fact that income from physical capital is an important income source for this group ${ }^{24}$. Moreover, the model predicts that, in this case, fertility would be an equalizing force for rich families.

One topic of future research that we intend to explore is the

\footnotetext{
and Doepke (2002).

${ }^{21}$ See Becker (1960), Simon (1974), Wahl (1985) and Schultz (1997).

${ }^{22}$ See Mincer (1963), Willis (1973), Mulligan (1993) and Schultz (1997).

${ }^{23}$ Willis (1973) and Simon (1974) find a U-shaped relationship between income and fertility for the United States. Ben-Porath (1973) finds the same pattern for Israel. Mulligan (1997) presents some evidence that fertility and income are positively related for rich families in the United States.

${ }^{24}$ See Mulligan (1997) for some evidence on the quantitative importance of asset income for rich families.
} 
A Competitive Growth Model with Endogenous Fertility

empirical evaluation of these implications of the model. Another interesting possibility would be to analyze whether differences in income composition between poor and rich families may account for the observed nonlinearities in the empirical relationship between fertility and income, and to derive the associated implications for the distribution of income in the long run.

\section{Appendix.}

\section{A.1. Proof of Lemma 1}

Let $\Omega\left(c_{i}, \lambda\right) \equiv \frac{m\left(c_{i}, \lambda\right)}{c_{i}}$

If we divide both sides of (28) by $c_{i}$ and rearrange the terms, we obtain:

$$
\Omega\left(c_{i}, \xi(R)\right)=\frac{1}{R[1-\varphi(\xi(R))]}+\frac{\phi R-w}{R[1-\varphi(\xi(R))] c_{i}}
$$

From assumption 1 and assumption 3, the right-hand side of (A1) is strictly decreasing in $c_{i}$.

Differentiating $\Omega\left(c_{i}, \xi(R)\right)$, with respect to $c_{i}$ we obtain:

$$
\Omega_{c}\left(c_{i}, \xi(R)\right)=\left[\xi\left(c_{i}, \xi(R)\right)-1\right] \frac{m\left(c_{i}, \xi(R)\right)}{c_{i}^{2}}
$$

From assumption 4 and (A2), $\Omega\left(c_{i}, \xi(R)\right)$ is weakly increasing in $c_{i}$ at the steady state solution, so the left-hand side of $(\mathrm{A} 1)$ is weakly increasing in $c_{i}$ at any such solution. Since the right-hand side of $(\mathrm{A} 1)$ is strictly decreasing in $c_{i}$, there exists at most one $c_{i}$ satisfying (A1).

A.2. Proof that Definition 4 is equivalent to the condi$\operatorname{tion} \hat{W}_{c} \hat{W}_{c n}-\left(\hat{W}_{n}+\varphi^{\prime} g\right) \hat{W}_{c c} \geq 0$. 
The first-order conditions associated with (30) are given by

$$
\begin{aligned}
& \hat{W}_{n}(c(I), n(I))+\varphi^{\prime}(n(I)) u=\left(\phi+k^{\prime}\right) \hat{W}_{c}(c(I), n(I)) \\
& c(I)+\left(\phi+k^{\prime}\right) n(I)=I
\end{aligned}
$$

where we express the optimal solutions for $c$ and $n$ as functions of $I$. Differentiating (A3) with respect to $I$ and using matrix notation, we obtain

$$
A\left[\begin{array}{l}
\frac{d c}{d I} \\
\frac{d n}{d I}
\end{array}\right]=\left[\begin{array}{l}
0 \\
1
\end{array}\right]
$$

where $A \equiv\left[\begin{array}{cc}\hat{W}_{c n}-\left(\phi+k^{\prime}\right) \hat{W}_{c c} & \hat{W}_{n n}+u \varphi^{\prime \prime}-\left(\phi+k^{\prime}\right) \hat{W}_{c n} \\ 1 & \phi+k^{\prime}\end{array}\right]$. Solving (A4) for $\frac{d n}{d I}$ using Cramer's Rule, we obtain

$$
\frac{d n}{d I}=\frac{\hat{W}_{c n}-\left(\phi+k^{\prime}\right) \hat{W}_{c c}}{\operatorname{det}(A)}
$$

From the second-order conditions, we have $\operatorname{det}(A)>0$. From (A3) and (A5), we have

$$
\frac{d n}{d I} \geq 0 \Leftrightarrow \hat{W}_{c} \hat{W}_{c n}-\left(\hat{W}_{n}+\varphi^{\prime} g\right) \hat{W}_{c c} \geq 0
$$

where we used the fact that $u=g(c, n)$. This establishes the condition in the text.

A.3. Proof that Definition 5 is equivalent to the condition $\hat{W}_{c} \varphi^{\prime} \geq 0$.

The first-order conditions associated with (30) are given by 
A Competitive Growth Model with Endogenous Fertility

$$
\begin{aligned}
& \hat{W}_{n}(c(u), n(u))+\varphi^{\prime}(n(u)) u=\left(\phi+k^{\prime}\right) \hat{W}_{c}(c(u), n(u)) \\
& c(u)+\left(\phi+k^{\prime}\right) n(u)=I
\end{aligned}
$$

where we express the optimal solutions for $c$ and $n$ as functions of $u$. Differentiating (A6) with respect to $u$ and using matrix notation, we obtain

$$
A\left[\begin{array}{l}
\frac{d c}{d u} \\
\frac{d n}{d u}
\end{array}\right]=\left[\begin{array}{c}
-\varphi^{\prime} \\
0
\end{array}\right]
$$

Solving (A7) for $\frac{d \pi}{d u}$ using Cramer's Rule, we obtain

$$
\frac{d n}{d u}=\frac{\varphi^{\prime}}{\operatorname{det}(A)}
$$

Since $\operatorname{det}(A)>0$ and $\hat{W}_{c}>0$, we obtain from (A8):

$$
\frac{d n}{d u} \geq 0 \Leftrightarrow \hat{W}_{c} \varphi^{\prime} \geq 0
$$

which establishes the condition in the text. $\square$

\section{A.4. Proof of Proposition 1}

From Lemma 1 , in any steady state we can define $c_{i}=\pi(R, w)$ and $\lambda=\xi(R)$. From (24), we obtain:

$$
k_{i}=\frac{\pi(R, w)+\phi \xi(R)-w}{R-\xi(R)}
$$

From (A9), it is clear that $k_{i}=k_{j} \quad \forall i, j=1, \ldots, M$.

A.5. Proof that Definition 6 is equivalent to the condition 


$$
\left(\hat{W}_{n}+\varphi^{\prime} g\right) \hat{W}_{c n}-\hat{W}_{c}\left(\hat{W}_{n n}+\varphi^{\prime \prime} g\right) \geq 0 \text {. }
$$

Solving (A4) for $\frac{d c}{d I}$ using Cramer's Rule, we obtain

$$
\frac{d c}{d I}=\frac{\left(\phi+k^{\prime}\right) \hat{W}_{c n}-\left(\hat{W}_{n n}+\varphi^{\prime \prime} u\right)}{\operatorname{det}(A)}
$$

From the second-order conditions, we have $\operatorname{det}(A)>0$. From (A3) and (A10), we have

$$
\frac{d c}{d I} \geq 0 \Leftrightarrow\left(\hat{W}_{n}+\varphi^{\prime} g\right) \hat{W}_{c n}-\hat{W}_{c}\left(\hat{W}_{n n}+\varphi^{\prime \prime} g\right) \geq 0
$$

where we used the fact that $u=g(c, n)$. This establishes the condition in the text.

\section{A.6. Proof of Lemma 2.}

If we differentiate (33) implicitly with respect to $\bar{k}$, we obtain

$$
\begin{aligned}
{\left[\Omega_{c}+\frac{(\phi-\Gamma)}{(1-\varphi) c_{i}^{2}}\right] C^{\prime}(\bar{k}) } & =-\frac{R^{\prime}(\bar{k})}{(1-\varphi) R^{2}}-\frac{\Gamma^{\prime}(\bar{k})}{(1-\varphi) c_{i}}+ \\
& +\frac{R \varphi^{\prime} \xi^{\prime}\left[c_{i}+(\phi-\Gamma) R\right] R^{\prime}(\bar{k})}{(1-\varphi)^{2} R^{2} c_{i}}-\Omega_{n} \xi^{\prime} R^{\prime}
\end{aligned}
$$

Since $\Gamma\left(\bar{k} \equiv \frac{w(\bar{k})}{R(\bar{k})}\right.$, we have $\Gamma^{\prime}\left(\bar{k}-\frac{R^{2}}{R^{2}}\right.$. om , we have $R^{\prime}(\bar{k})=f^{\prime \prime}(\bar{k})$. From (20), we have $w^{\prime}(\bar{k})=-\bar{k} R^{\prime}(\bar{k})$. This implies that

$$
\Gamma^{\prime}(\bar{k})=\frac{-[w(\bar{k})+\bar{k} R(\bar{k})] R^{\prime}(\bar{k})}{R^{2}}
$$


A Competitive Growth Model with Endogenous Fertility

From (19) and (20) and the equation above, we obtain

$$
\Gamma^{\prime}(\bar{k})=\frac{-[f(\bar{k})+(1-\delta) \bar{k}] R^{\prime}(\bar{k})}{R^{2}}
$$

If we substitute (A12) into the right-hand side of (A11) and rearrange the terms, we obtain

$$
C^{\prime}(\bar{k})=\frac{\left[\frac{(1-\varphi)\left[f(\bar{k})+(1-\delta) \bar{k}-c_{i}\right]+R \varphi^{\prime} \xi^{\prime}\left[c_{i}+(\phi-\Gamma) R\right]}{(1-\varphi)^{2} R^{2} c_{i}}-\Omega_{n} \xi^{\prime}\right]}{\left[\Omega_{c}+\frac{\phi-\Gamma}{(1-\varphi) c_{i}^{2}}\right]} R^{\prime}(\bar{k})
$$

The denominator of (A13) is positive, since $\Omega_{c} \geq 0$ (which follows from assumption 4), $\phi-\Gamma>0$ (which is equivalent to assumption 3 ) and $\varphi \in(0,1)$, which follows from assumption 1 . The term $\Omega_{n}$ in the numerator is the derivative of $\Omega$ with respect to $n$, evaluated at $\lambda$, which is equal to:

$$
\Omega_{n}=\frac{\hat{W}_{c}\left(\hat{W}_{n n}+\varphi^{\prime \prime} g\right)-\left(\hat{W}_{n}+\varphi^{\prime} g\right) \hat{W}_{c n}}{\left(\hat{W}_{c}\right)^{2} c_{i}}
$$

which is negative from assumption 5 . From the feasibility condition (18), we have $f(\bar{k})+(1-\delta) \bar{k}>c_{i}$. Since $\xi^{\prime}>0$ and $\varphi^{\prime}>0$, the term inside brackets in the numerator of (A13) is strictly positive. Since $R^{\prime}(\bar{k})=f^{\prime \prime}(\bar{k})<0$, we have established that $C^{\prime}(\bar{k})<0$.

\section{A.7. Proof of Proposition 2.}

If we view both sides of (35) as functions of $\bar{k}$, the right-hand side is the 45-degree line. If we differentiate (34) implicitly with respect to $\bar{k}$, we obtain 


$$
\Psi^{\prime}(\bar{k})=\frac{C^{\prime}(\bar{k})+\phi \lambda^{\prime}(\bar{k})-w^{\prime}(\bar{k})-\frac{\left(c_{i}+\phi \lambda-w\right)}{R-\lambda}\left[R^{\prime}(\bar{k})-\lambda^{\prime}(\bar{k})\right]}{R-\lambda}
$$

From (19), we have $R^{\prime}(\bar{k})=f^{\prime \prime}(\bar{k})$. From (20), we have $w^{\prime}(\bar{k})=$ $-\bar{k} R^{\prime}(\bar{k})$. Substituting these expressions with (19) and (24) into (A14), we obtain

$$
\Psi^{\prime}(\bar{k})=\frac{C^{\prime}(\bar{k})+\left(\phi+k_{i}\right) \lambda^{\prime}(\bar{k})+f^{\prime \prime}(\bar{k})\left(\bar{k}-k_{i}\right)}{1-\delta+f^{\prime}(\bar{k})-\lambda}
$$

At the steady state, $k_{i}=\bar{k}$, which reduces $(\mathrm{A} 15)$ to

$$
\Psi^{\prime}(\bar{k})=\frac{C^{\prime}(\bar{k})+\left(\phi+k_{i}\right) \lambda^{\prime}(\bar{k})}{1-\delta+f^{\prime}(\bar{k})-\lambda}
$$

Since $C^{\prime}(\bar{k})<0$ from (A13), $\lambda^{\prime}(\bar{k})<0$ from (32) and $1-\delta+$ $f^{\prime}(\bar{k})-\lambda=R(1-\varphi)>0$, from assumption 1 , we obtain that the function $\Psi(\bar{k})$ has a negative slope when it crosses the 45-degree line, which implies that it can cross it only once, establishing the desired result.

Submitted in August 2002. Revised in January 2003.

\section{References}

Alvarez, F. 1999. "Social Mobility: The Barro-Becker Children Meet the Laitner-Loury Dynasties". Review of Economic Dynamics 2:65-103. 
A Competitive Growth Model with Endogenous Fertility

Barro, R. \& G. S. Becker 1989. "Fertility Choice in a Model of Economic Growth". Econometrica 57:481-501.

Becker, G. S. 1960. "An Economic Analysis of Fertility". In: Demographic and Economic Change in Developed Countries. Princeton University Press.

Becker, G. S. \& G. H. Lewis 1973 . "On the Interaction between the Quantity and Quality of Children". Journal of Political Economy 81:279-288.

Becker, G. S., \& R. Barro 1988. "A Reformulation of the Economic Theory of Fertility". Quarterly Journal of Economics 103:1-25.

Becker, G. S., K. M. Murphy, \& R. F. Tamura 1990. "Economic Growth, Human Capital, and Population Growth". Journal of Political Economy 98:S12-S37.

Benhabib, J., \& K. Nishimura 1993. "Endogenous Fertility and Growth". In: General Equilibrium, Growth, and Trade II, The Legacy of Lionel McKenzie, Edited by R. Becker, M. Boldrin, R. Jones, and $\mathrm{W}$. Thomson. Academic Press Inc.

Ben-Porath, Y. 1973. "Economic Analysis of Fertility in Israel: Point and Counterpoint". Journal of Political Economy 81 (2):S202-S233.

Dahan, M. \& D. Tsiddon 1998. "Demographic Transition, Income Distribution, and Economic Growth". Journal of Economic Growth 3:29-52.

Doepke, M. 2002. "Inequality and Growth: Why Differential Fertility Matters". Working Paper, Department of Economics, UCLA.

Dolmas, J. 1996. "Balanced-Growth-Consistent Recursive Utility". Journal of Economic Dynamics and Control 20:657-680.

Kremer, M. \& D. Chen 2000. "Income Distribution Dynamics with Endogenous Fertility". NBER Working Paper 7530. 
Lucas, R. E., Jr. 2002. Lectures on Economic Growth. Harvard University Press.

Lucas, R. E., Jr., \& N. L. Stokey 1984. "Optimal Growth with Many Consumers". Journal of Economic Theory 32: 139-171.

Mincer, J. 1963. "Market Prices, Opportunity Costs, and Income Effects". In: Measurement in Economics. Edited by C. F. Christ et al. Stanford, Stanford University Press.

Mulligan, C. B. 1993. "Intergenerational Altruism, Fertility, and the Persistence of Economic Status". Ph.D. Dissertation, Department of Economics, University of Chicago.

Mulligan, C. B. 1997. Parental Priorities and Economic Inequality. The University of Chicago Press.

Razin, A. \& U. Ben-Zion 1975. "An Intergenerational Model of Population Growth". American Economic Review 65: 923-933.

Schultz, T. P. 1997. "Demand for Children in Low Income Countries" in Handbook of Population and Family Economics, ed. by M. R. Rosenzweig and O. Stark, Elsevier Science.

Simon, J. L. 1974. The Effects of Income Upon Fertility. Monograph no. 19. Chapel Hill: Carolina Population Center, University of North Carolina.

Stokey, N. L. \& R. E. Lucas, Jr. 1989. Recursive Methods in Economic Dynamics. Harvard University Press.

Wahl, J. B. 1985. "Fertility in America: Historical Patterns and Wealth Effects on the Quantity and Quality of Children". Ph.D. Dissertation, Department of Economics, University of Chicago. Willis, R. J. 1973. "A New Approach to the Economic Theory of Fertility Behavior". Journal of Political Economy 81:S14-S64. 
